\title{
TRANSFORMING HEALTH SYSTEMS THROUGH GOOD DIGITAL HEALTH GOVERNANCE
}

Alvin Marcelo, Donna Medeiros, Kirthi Ramesh, Susann Roth, and Pamela Wyatt

NO. 51

February 2018
ADB SUSTAINABLE DEVELOPMENT WORKING PAPER SERIES 


\section{ADB Sustainable Development Working Paper Series}

\section{Transforming Health Systems Through Good Digital Health Governance}

Alvin Marcelo, Donna Medeiros, Kirthi Ramesh, Susann Roth, and Pamela Wyatt

No. 51 | February 2018
Alvin B. Marcelo is an associate professor of surgery and health informatics and concurrently the executive director of the Asia eHealth Information Network (AeHIN)

Donna Medeiros is a consultant for ADB's Sustainable Development and Climate Change Department (SDCC) specializing in digital health architecture and policy.

Kirthi Ramesh is a social development specialist in ADB's Sustainable Development and Climate Change Department (SDCC).

Susann Roth is senior social development specialist (Social Protection) in ADB's Sustainable Development and Climate Change Department (SDCC).

Pamela Wyatt is principal public management specialist (Governance) in ADB's Pacific Department. 
(C) 2018 Asian Development Bank

6 ADB Avenue, Mandaluyong City, 1550 Metro Manila, Philippines

Tel +63 2632 4444; Fax +6326362444

www.adb.org

Some rights reserved. Published in 2018.

Publication Stock No. WPS189244-2

DOI: http://dx.doi.org/10.22617/WPS189244-2

The views expressed in this publication are those of the authors and do not necessarily reflect the views and policies of the Asian Development Bank (ADB) or its Board of Governors or the governments they represent.

$A D B$ does not guarantee the accuracy of the data included in this publication and accepts no responsibility for any consequence of their use. The mention of specific companies or products of manufacturers does not imply that they are endorsed or recommended by ADB in preference to others of a similar nature that are not mentioned.

By making any designation of or reference to a particular territory or geographic area, or by using the term "country" in this document, $A D B$ does not intend to make any judgments as to the legal or other status of any territory or area.

This work is available under the Creative Commons Attribution 3.0 IGO license (CC BY 3.0 IGO) https://creativecommons.org/licenses/by/3.0/igo/. By using the content of this publication, you agree to be bound by the terms of this license. For attribution, translations, adaptations, and permissions, please read the provisions and terms of use at https://www.adb.org/terms-use\#openaccess.

This CC license does not apply to non-ADB copyright materials in this publication. If the material is attributed to another source, please contact the copyright owner or publisher of that source for permission to reproduce it. $A D B$ cannot be held liable for any claims that arise as a result of your use of the material.

Please contact pubsmarketing@adb.org if you have questions or comments with respect to content, or if you wish to obtain copyright permission for your intended use that does not fall within these terms, or for permission to use the ADB logo.

Notes:

In this publication, “\$” refers to US dollars.

Corrigenda to ADB publications may be found at http://www.adb.org/publications/corrigenda. 


\section{CONTENTS}

Figures

Abstract

I. Information and Communication Technology is Transforming Health Care 1

II. Strong Governance is Key to Making Digital Health Investments 3

III. COBIT 5 for Good Governance of Digital Health Enterprises 5

IV. Governance for Digital Health in Asia and the Pacific: HIGAF 2.0

$\begin{array}{lr}\text { V. Stakeholders, Governance Structure, and Processes } & 9\end{array}$

$\begin{array}{ll}\text { VI. Steps to Strong Digital Health Governance } & 13\end{array}$

$\begin{array}{ll}\text { APPENDIX } & 14\end{array}$ 


\section{FIGURES}

1 Average Broadband Speed in Asia 1

2 Percentage of Survey Respondents Using 4G Networks to Access the Internet 2

3 Principles of Good Digital Health Governance 3

4 Cycle of Good Governance, Digital Health, and Health Systems 4

5 The Cascade of Health Sector Goals 5

6 Enablers of Digital Health 6

7 Digital Health Enterprise $\quad 7$

8 Health ICT Governance Architecture Framework $2.0 \quad 8$

9 Governance Components 9

10 A Complex Web of Stakeholders Enables Digital Health 10

11 Moving Towards a Polycentric and Patient-Centric Governance for Digital Health 11

12 Governance Models 12

13 Differentiating Governance and Management 12 


\begin{abstract}
Information and communication technology (ICT) in the health system, also known as digital health, can accelerate health system reforms, leading to better-quality, efficient, and accessible patient-centered care. Digital health has been acknowledged by the World Health Organization as a key building block for universal health coverage and the health-related Sustainable Development Goals, and many countries are implementing solutions, such as digital disease surveillance systems, electronic medical records, and social health insurance payment processes. However, countries lack a holistic approach to digital health, which requires good governance for successful implementation and sustainability throughout the health system. Good digital health governance is the foundation that is required to coordinate stakeholders and policies that enable effective ICT for a well-functioning health system. Its ultimate objective is to maximize the achievement of health outcomes. ICT governance frameworks are already in use in various sectors and industries. They have helped to accelerate its transformational power in their respective industries, but the health sector still lags behind in adopting an ICT governance framework. This hinders the transformational effect of digital health investments. Together with partners, the Asian Development Bank developed a health ICT governance architecture framework (HIGAF). Consultations and close collaboration with health sector ICT experts in the region further refined the framework, leading to the creation of HIGAF 2.0, designed specifically to meet the evolving needs of developing member countries in the region. HIGAF 2.0 enables countries to prioritize the structures and processes that must be established to enable an enterprise (system-wide) approach, and cost-effective investments in digital health.
\end{abstract}





\section{INFORMATION AND COMMUNICATION TECHNOLOGY IS TRANSFORMING HEALTH CARE}

The strategic use of information and communication technology (ICT) can transform health systems. Digital health, often called eHealth, has been acknowledged by the World Health Organization (WHO) as a key building block for attaining universal health coverage (UHC). ${ }^{1}$ Across Asia and the Pacific, countries have committed to attaining the goal of UHC. As part of this process, they are grappling with how and when to harness digital health solutions to improve accessibility, quality, and affordability for the health system.

\section{Figure 1: Average Broadband Speed in Asia}

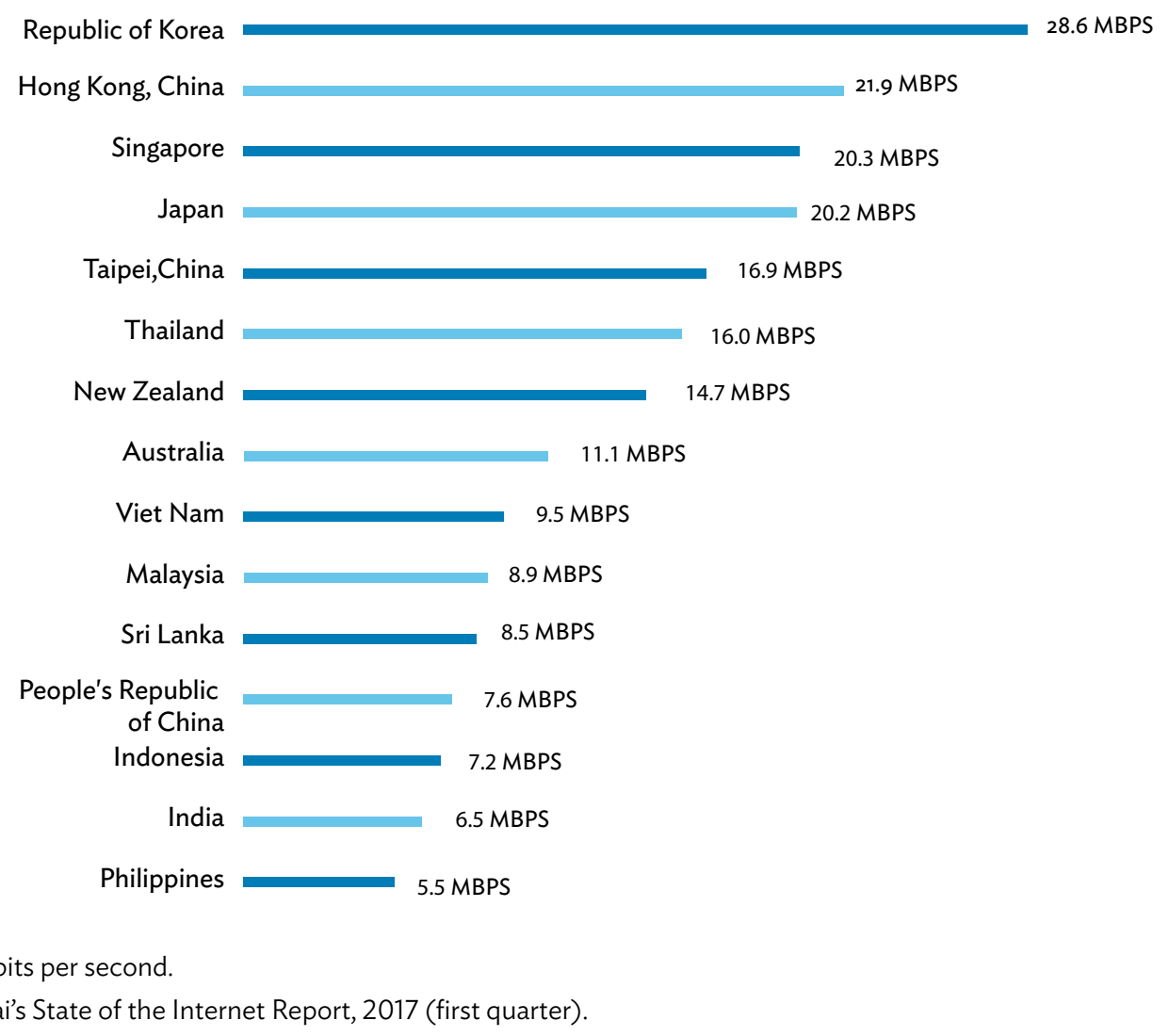

Source: Akamai's State of the Internet Report, 2017 (first quarter).

Two factors are significantly contributing to the growth of digital health solutions. First, access to ICT in Asia and the Pacific is at unprecedented levels and growing. Broadband coverage has become increasingly prevalent in the region, and speeds for both broadband and mobile data are getting faster by the year (Figure 1). ${ }^{2}$ By the end of 2015, 2.5 billion people were mobile phone subscribers-more

WHO. 2016. Global Observatory for eHealth, Global Diffusion of eHealth: Making Universal Health Coverage Achievable. http://apps.who.int/iris/bitstream/10665/252529/1/9789241511780-eng.pdf?ua=1.

2 Asia's mobile and broadband internet speeds, in one infographic. Tech in Asia. https://www.techinasia.com/asia-internet-speeds-mobile-broadband. (accessed 28 October 2017). 
than $60 \%$ of the population. Mobile phone penetration in the region continues to grow faster than the global average, with 600 million new subscribers expected by $2020 .{ }^{3}$ Use of $4 \mathrm{G}$ networks to access the internet via smartphones is also rapidly increasing (Figure 2). Second, demand for better health systems is growing as countries in the region mature. They are often providing services to large and geographically widely dispersed, and in some cases to migrant and highly mobile, populations. Countries understand the way health care is delivered must change. Together with shifting disease profiles, increasing income, changing lifestyles, and aging populations are increasing the need for chronic care for noncommunicable diseases. Such care is expensive and requires a shift in orientation, away from short-term treatment, towards health promotion and patient-centric chronic care.

Figure 2: Percentage of Survey Respondents Using 4G Networks to Access the Internet

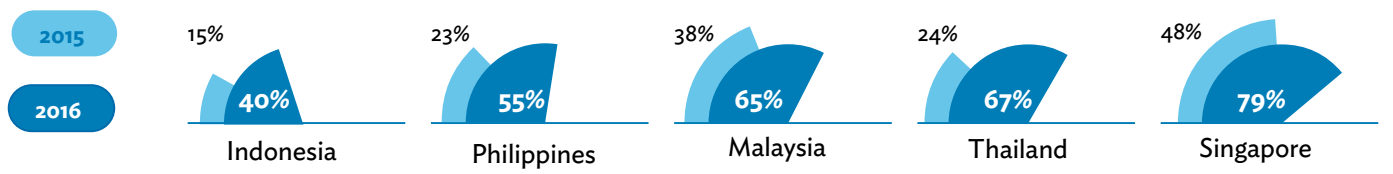

Source: Deloitte Global Mobile Consumer Survey, Southeast Asia edition, September 2016.

Countries in Asia and the Pacific are facing similar health information challenges. Lack of regulation and governance, weak national health informatics capacity, and fragmented information systems that do not take an enterprise approach are all common issues in the region. Many countries do not have a system of unique patient identification; funding priorities are not always set by the ministry of health $(\mathrm{MOH})$, and there is weak interagency and public-private collaboration.

However, increasing access to ICT, and in particular broadband and rapid advances in ICT solutions, raises the prospect of addressing these shortcomings and solving problems. For example, engaging digital communications can encourage community development and behavior change, and remote areas can be connected to expert care via telehealth. Health care workers have improved access to training and diagnostic and clinical decision-making support. Patient monitoring and care can be more patientcentered with the increased use of ICT. Digital health can transform record keeping, data sharing, and usage; enhance communication between patients and their providers; and improve service quality through more efficient resource allocation while lowering health care costs.

When properly implemented, digital health solutions within a health system enable different technology systems and software applications to work together, so systems for disparate providers can communicate, share data, and exchange information. While this interoperability helps enhance continuity of care, it can only be achieved with good digital health governance.

3 GSM Association. 2016. The Mobile Economy Asia Pacific 2016. https://www.gsmaintelligence.com/research/?file=5369c b14451e0db728bd266c7657a251\&download. 


\section{STRONG GOVERNANCE IS KEY TO MAKING DIGITAL HEALTH INVESTMENTS}

Once countries have begun to implement various digital health solutions, such as electronic medical records, social health insurance payment processes, and monitoring and evaluation systems, they have frequently found that poor governance has thwarted the opportunity for smart and strategic investment decisions to be effectively and efficiently implemented. They lack a holistic approach to digital health, and one which requires sound governance for successful nationwide sustainable rollout. In the absence of clear governance structures, policies, and processes, the roles and responsibilities are blurred, which results in fragmentation, wastage of resources, duplication of efforts, nonstrategic investment decisions, and a lack of common standards.

Digital health helping deliver UHC cannot be realized unless it is introduced within a solid governance framework with a clear digital strategy and architectural support for a country's overarching vision for health care. ${ }^{4}$ Without good governance, digital health systems may not sufficiently respond to needs and priorities of the health system, and cannot be managed in a transparent and accountable way. Strong governance makes the specific roles and responsibilities of each actor explicit; ensures that legislations, policies, and standards are applied across the digital health enterprise; and promotes good coordination mechanisms and decision making, and incentives to use digital health solutions. Good governance is needed at all levels - local, district, provincial, and national - throughout the health information system. This, in turn, supports equitable access and delivery of quality, affordable health services.

Figure 3: Principles of Good Digital Health Governance

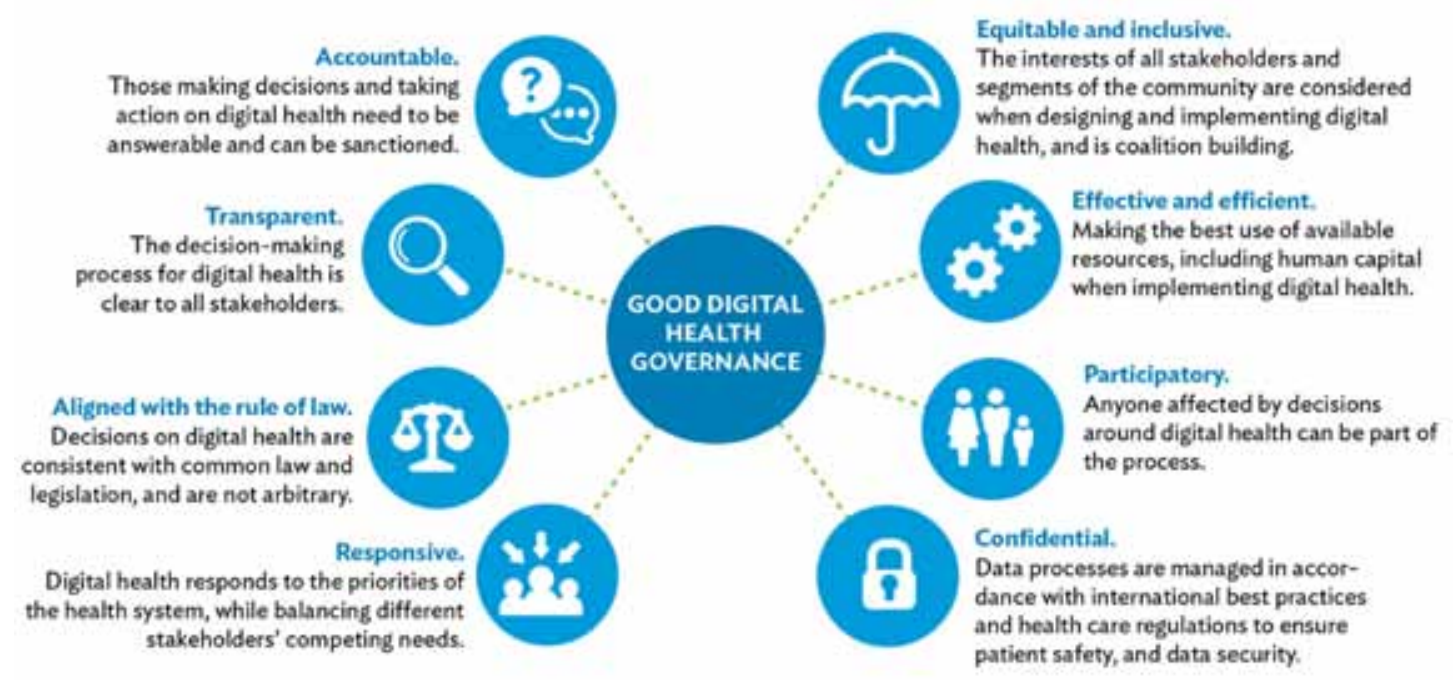

Source: Adapted from Good Governance Guide, which can be found in: http://www.goodgovernance.org.au/about-goodgovernance/what-is-good-governance/.

4 ISO/TR 14639-1:2012 Requirements of eHealth Architecture and COBIT 5. 
Good digital health governance is based on the principles of accountability, transparency, rule of law, responsiveness, equity and inclusiveness, effectiveness, efficiency, and participation, as well as confidentiality (Figure 3). ${ }^{5}$ It is the foundation for stakeholder coordination and policies that enable solutions and investments, avoid duplication and fragmentation, and harmonize efforts. Good digital health governance improves the functioning of health information systems to support broader health goals, and can transform the way health care is delivered today, moving from being care-focused to being health-focused. ${ }^{6}$

While digital health needs good governance, it also contributes to good governance of health systems (Figure 4). Accessible, high-quality health data produced through digital health enhances transparency and accountability of health systems. Giving communities access to health data can increase their participation, and ensure their needs are being met. Timely access to and use of quality data improves communicable disease surveillance, generates better-targeted health resource allocation, provides faster response to population health care needs (e.g. immunization campaigns), and supports monitoring quality of care.

\section{Figure 4: Cycle of Good Governance, Digital Health, and Health Systems}

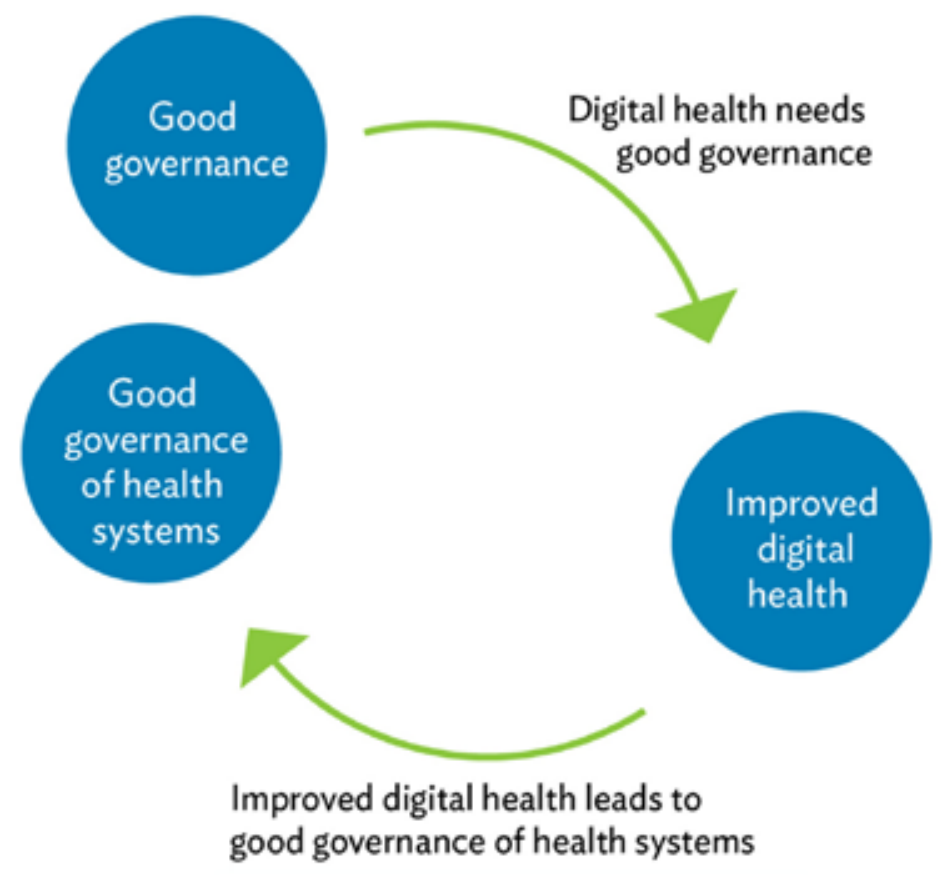

Source: Authors.

5 Different institutions use different sets of principles. An overview can be found in http://www.who.int/universal_health_ coverage/plan_action-hsgov_uhc.pdf?ua=1.

6 S. Sahay, T. Sundararaman, and J. Braa. 2017. Public Health Informatics, Designing for Change - A Developing Country Perspective. London. 


\section{COBIT 5 FOR GOOD GOVERNANCE OF DIGITAL HEALTH ENTERPRISES}

The ultimate objective of digital health governance is to enable a health system to use ICT to maximize achievement of health, as defined by the country's national health strategies and plans, as well as by global objectives such as UHC and the health-related Sustainable Development Goals (SDGs). Control Objectives for Information and Related Technologies 5 (COBIT 5) is a governance framework created by international professional association ISACA (Information Systems Audit and Control) for information technology (IT) management and governance. The goals cascade of COBIT 5 can explain how governance of digital health contributes to larger health sector goals (Figure 5). Indicators can be formulated at every level of COBIT 5 to monitor how effectively the digital system supports those higher health sector goals.

The purpose of a health system is to provide quality, affordable, accessible, equitable, and efficient health care (enterprise goals). This, in turn, drives the need for digital health (IT-related goals) (Figure 5).

Figure 5: The Cascade of Health Sector Goals

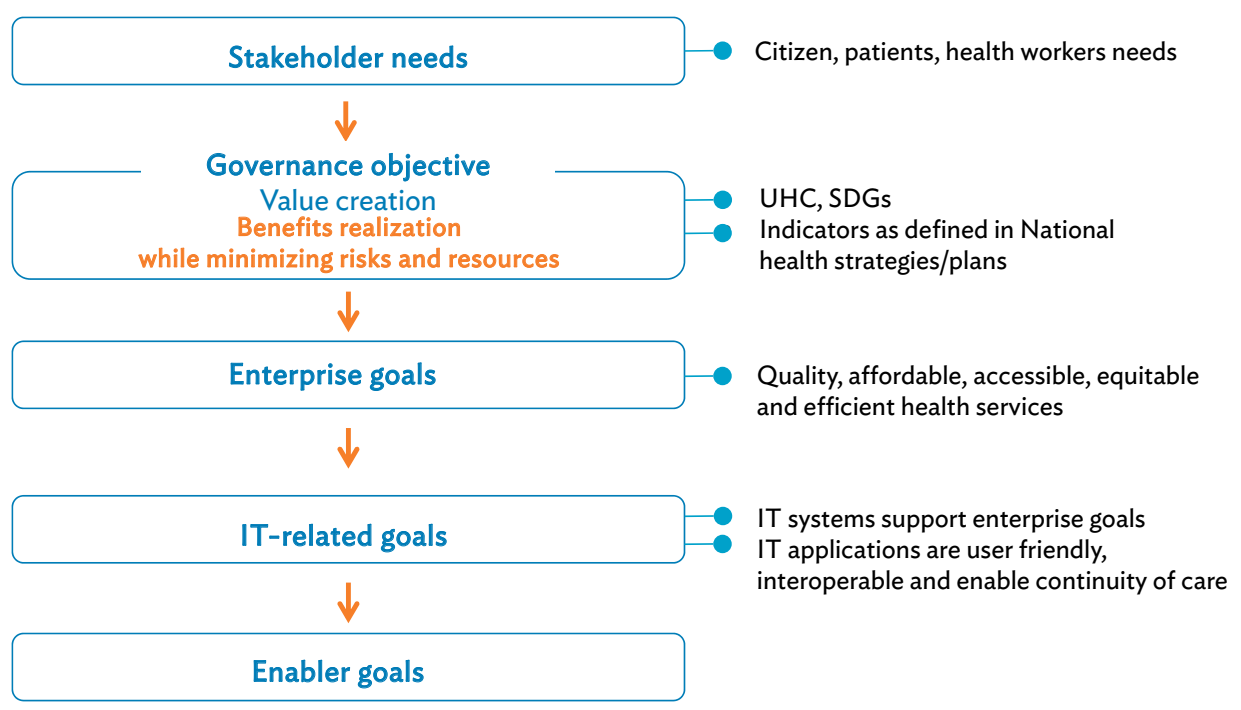

IT = information technology, SDG = Sustainable Development Goal, UHC = universal health coverage.

Source: Adapted from COBIT 5.

According to COBIT 5, there are several enabling factors (enabler goals) supporting the achievement of IT-related and enterprise goals (Figure 5). They include a series of governance mechanisms, which inform how to govern and what to govern (Figure 6). 


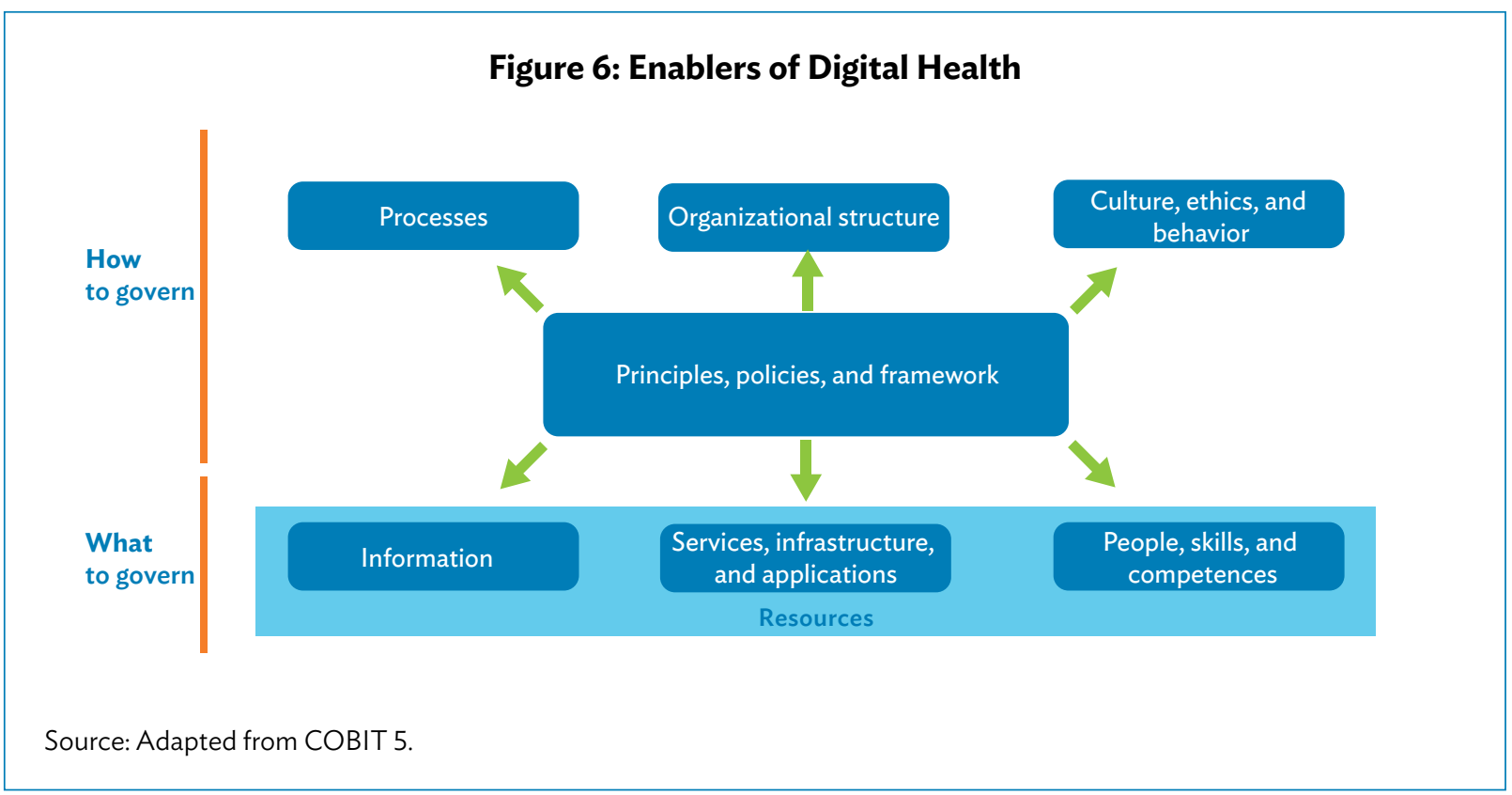

\section{GOVERNANCE FOR DIGITAL HEALTH IN ASIA AND THE PACIFIC: HIGAF 2.0}

Together with its partners, the Asian Development Bank (ADB) has identified a growing need for a digital health information governance architecture framework (HIGAF) designed to meet the needs of developing member countries and enable health sectors to use existing IT governance initiatives to drive digital health. The key desire driving HIGAF is for countries to establish a holistic approach to integrated health information system management based on a digital health enterprise, an end-to-end system, (Figure 7) with connected and interoperable, information systems allowing the flow of health data. The Asia eHealth Information Network (AeHIN), a peer-led network of digital health experts from government, civil society, the private sector, developed countries, development partners, and academia in more than 25 countries and ADB can assist countries to develop and implement HIGAF 2.0.

Governance is one of the key pillars of AeHIN's digital health agenda, together with architecture, program management, and standards. AeHIN was looking at other ICT governance frameworks to help find practical guidance for governing a digital health enterprise. However, countries' feedback showed that existing ICT governance frameworks were too complex and not fully applicable to the health sector. 


\section{Figure 7: Digital Health Enterprise}

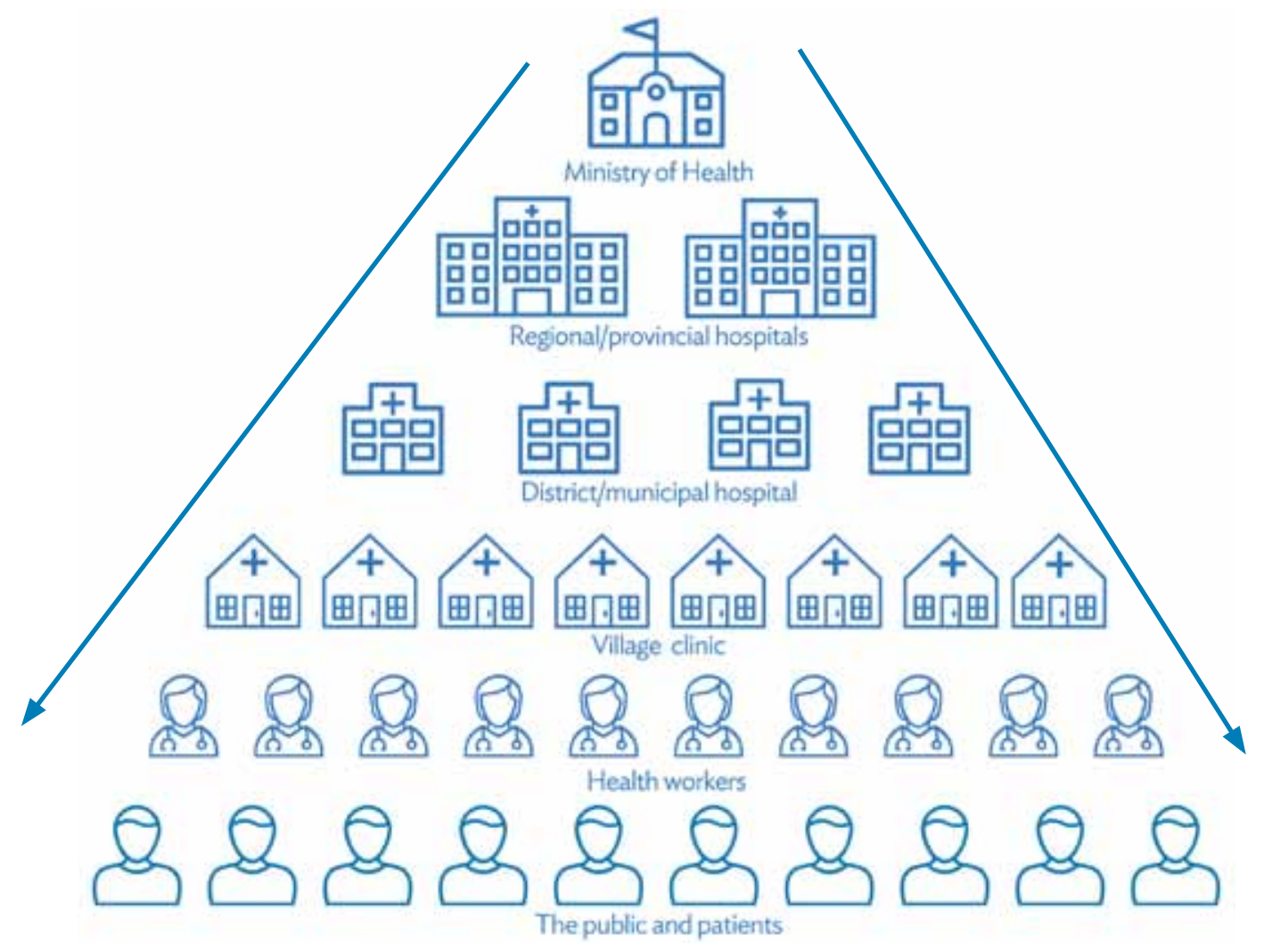

Source: Authors.

AeHIN and ADB worked together to distill the key elements of existing frameworks and adapted them to meet the needs of health sector. Taking note of lessons learned at a training course on digital health governance in September 2017, HIGAF 2.0 was developed in close collaboration with health sector ICT experts in the region.

HIGAF 2.0 simplifies key elements of COBIT 5 and combines them with digital health resources, including the WHO and International Telecommunication Union National (ITU) eHealth Strategy Toolkit and the Broadband Commission report Digital Health: A Call for Government Leadership and Cooperation between ICT and Health (Figure 8).,8 The framework is further informed by a global repository of digital health standards, policies and architecture artefacts (Appendix), stakeholder mapping and the principles of good governance.

7 WHO/ITU. National eHealth Strategy Toolkit Overview. http://www.who.int/ehealth/publications/overview.pdf?ua=1.

8 Broadband Commission Working Group on Digital Health. Digital Health: A Call for Government Leadership and Cooperation between ICT and Health. http://www.broadbandcommission.org/Documents/publications/WorkingGroupHealthReport-2017.pdf. 
Figure 8: Health ICT Governance Architecture Framework 2.0

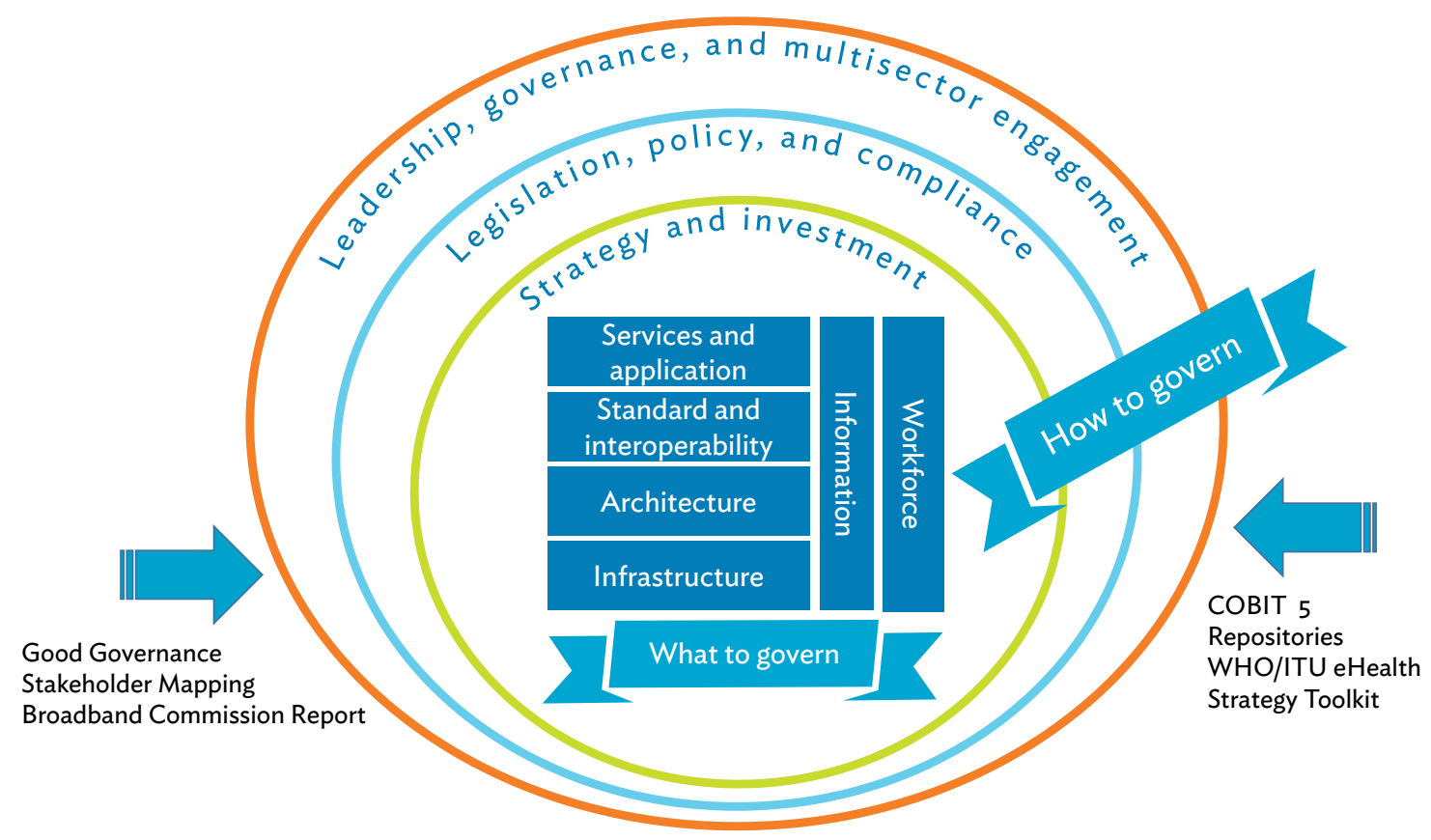

WHO = World Health Organization .

Source: Adapted from WHO/ITU National eHealth Strategy Toolkit.

In HIGAF 2.0, the seven components of the WHO/ITU eHealth Strategy Toolkit have been expanded to include information and architecture and divided into: what to govern and how to govern (Figure 8).

How to govern. There are three tiers that encircle the entire framework. They represent three digital health components from the WHO/ITU eHealth Strategy Toolkit, which describe how to govern. The first tier is leadership, governance and multisector engagement. Without this in place, no system-wide decision can be made. This layer represents the steering and stakeholder coordination function of the framework (direct, coordinate digital health, align with health goals, engage stakeholders, implement, and monitor).

The second tier covers the governance process (legislation, policy, and compliance), which create the enabling environment to ensure IT policies are aligned across sectors and across the country, and that laws are enforced. This is a key component of establishing trust and protection for both the public and the health sector workforce. It includes, for example, laws and policies on data standards, privacy and security.

The third tier is strategy and investment, which ensures that financing priorities are aligned across governments, donor agencies, and the private sector. As part of the governance framework, there should be a national digital health strategy, defined by the national health strategy, policies, and plans. This strategy defines the digital health enterprise goal. Once this strategic vision is established, a strong and functional governance structure can be put in place. 
What to govern. At the center of the framework, there are six digital health components that need to be governed. Both workforce use of ICT and the information generated, stored, and retrieved must be included as components of digital health, which require governance. They are depicted separately as they can also be seen as enablers of digital health. Governance then applies to infrastructure, architecture, standards and interoperability, and services and applications. ${ }^{9}$

By pulling together key resources into one framework, it is possible to understand, and separate the component of governance, which falls into three main categories: process, structure, and stakeholders (Figure 9).

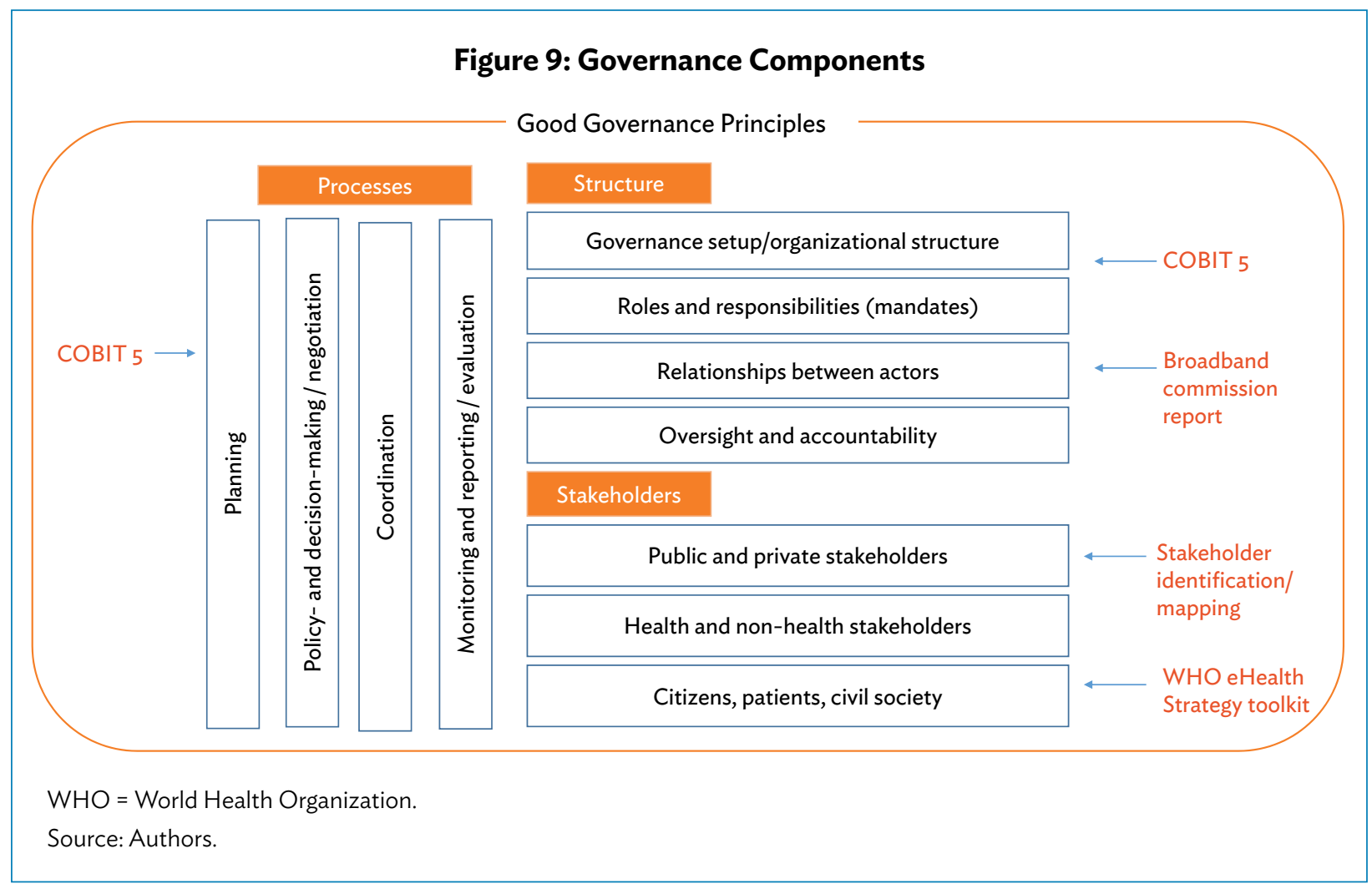

\section{STAKEHOLDERS, GOVERNANCE STRUCTURE, AND PROCESSES}

Stakeholders. A complex web of stakeholders are included in digital health: government ministries, decentralized levels of government, civil society organizations, the private sector, and service providers (Figure 10). Stakeholders enabling digital health are found beyond the health sector and include private providers, civil society organizations, private vendors, and nonhealth line ministries such as the ministry of ICT and ministry of finance (Figure 10).

9 A description of all these components is in the WHO and ITU National eHealth Strategy Toolkit. https://www.itu.int/ dms_pub/itu-d/opb/str/D-STR-E_HEALTH.05-2012-PDF-E.pdf. 


\section{Figure 10: A Complex Web of Stakeholders Enables Digital Health}

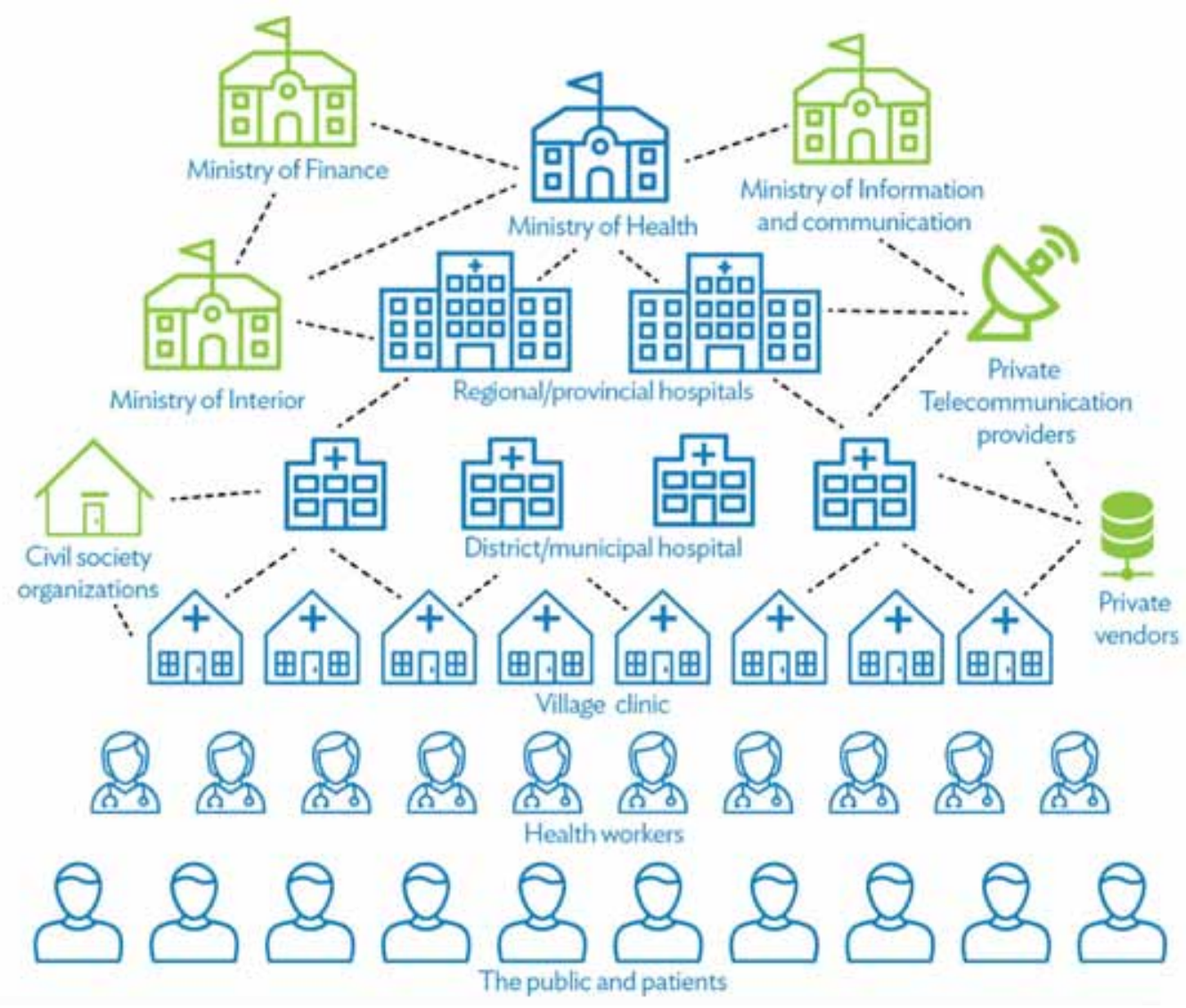

Source: Authors.

To be effective, a governance framework must take into account the main stakeholders in health service delivery, and in health care financing, consider public spending, out-of-pocket expenditure, and donor funding, as well as health insurance mechanisms. Frontline health workers and patients are important users and beneficiaries of digital health. Their feedback should be sought in planning and implementing digital health.

Mapping and understanding stakeholders is an important first step to decide how to engage with different stakeholders and establish a governance structure (see below). Stakeholder mapping is a three-step process: (i) identify stakeholders with roles in policy- and decision-making and implementation in and beyond the health sector; (ii) identify those who will use and will be affected by digital health solutions; and (iii) identify those who bring in key resources (human, financial, and technological). Different stakeholders need digital health solutions for different purposes and may have different investment priorities. These should be well understood. The WHO and International Telecommunication Union National eHealth Strategy Toolkit gives guidance on how to map, engage, and consult different stakeholder groups in creating an eHealth vision. The ADB guidance document on investing in digital health provides insights into the array of benefits stakeholders expect from digital health.

Nationwide implementation of digital health is particularly important where more and more patient-centric data is exchanged. Eventually, this will lead to a health information web requiring polycentric and diffused forms of governance, which are less hierarchical, but more patient-centered (Figure 11). 
Figure 11: Moving Towards a Polycentric and Patient-Centric Governance for Digital Health
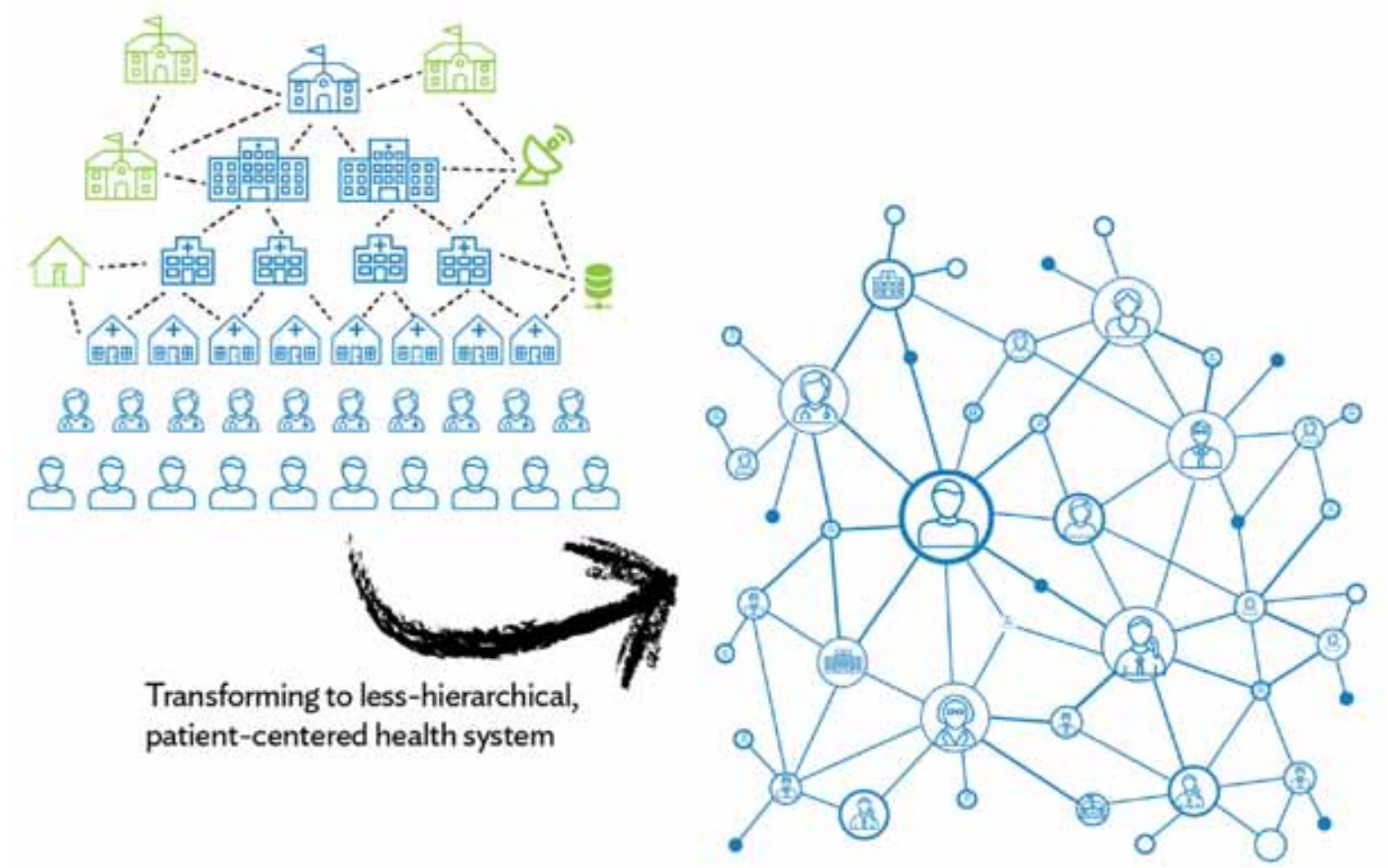

Source: Authors.

Governance structure. The structure defines the roles and responsibilities of different stakeholders. Even in diffused forms of governance, the health enterprise, with the $\mathrm{MOH}$ at its core, needs to maintain a central role in regulatory functions such as policy making, coordination, and standard-setting. Its role may need to be defined in more detail depending on the context.

When put into action, a digital health governance framework has to reflect the power relations and lines of accountability between the different stakeholders. For example, if the central actor responsible for defining standards is hierarchically lower than other stakeholders running digital health, it might not have sufficient leverage to incentivize them to implement the digital health standards, making effective nationwide implementation difficult. In COBIT 5, establishing a governance structure is one of the first steps to be taken. The Broadband Commission has proposed three different governance models for digital health in its report that can be used for reference (Figure 12):

- Under the $\mathrm{MOH}$ mechanism, digital health is driven from within the $\mathrm{MOH}$, which then mobilizes technical capacity and skills from other ministries.

- Under the government-wide digital agency mechanism, the $\mathrm{MOH}$ drives digital health, but a government-wide agency provides ICT infrastructure capacity.

- In the third model, the MOH leads health strategy, but ICT is designed by a third-party agency. 


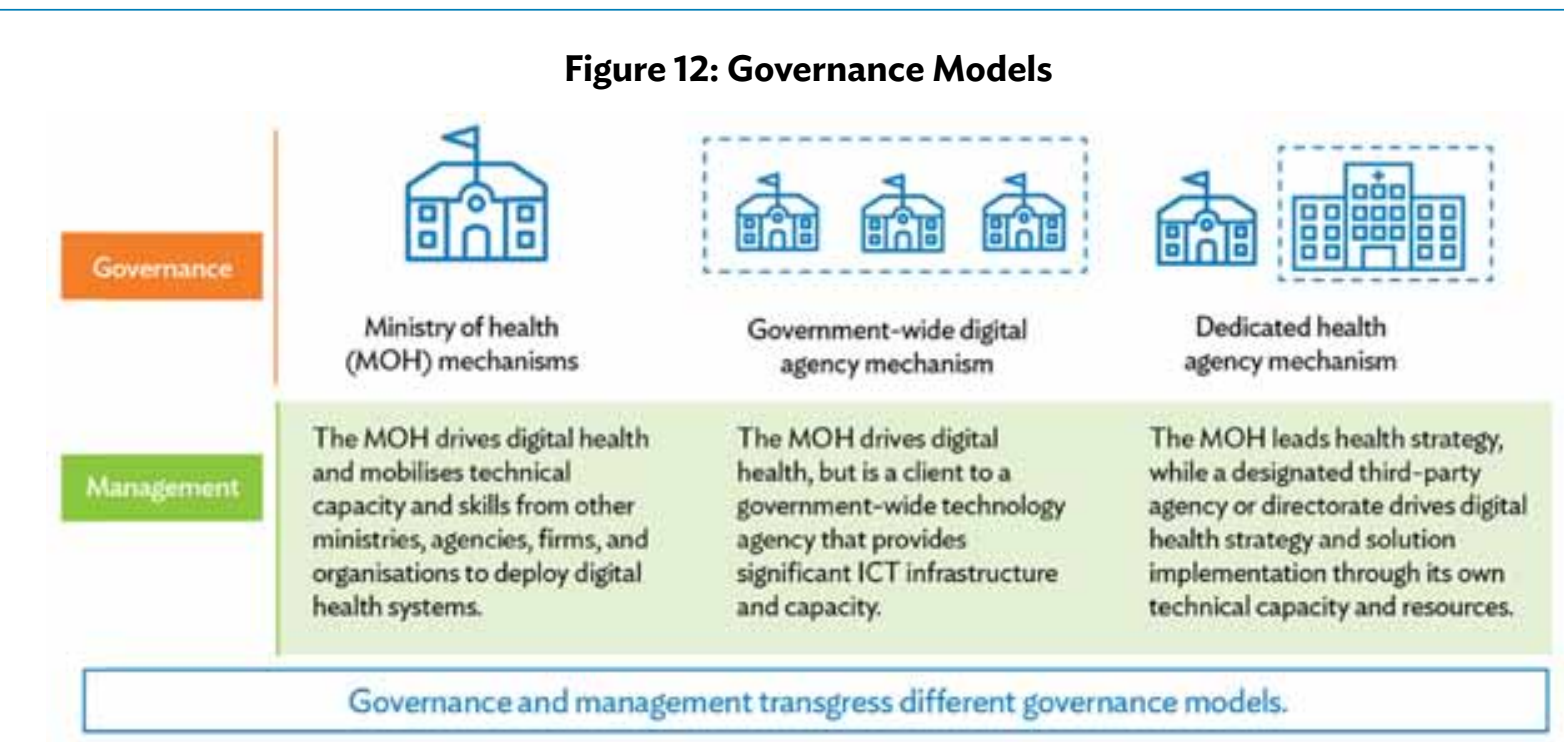

ICT = information and communication technology, $\mathrm{MOH}=$ ministry of health.

Source: Adapted from Broadband Commission report.

Processes. Governance processes encompass policy and decision making, planning, resource allocation, coordination, and monitoring and evaluation. These are usually driven by the digital health enterprise with the MOH at its core. HIGAF 2.0 draws from COBIT 5. In COBIT 5, processes are defined as "a set of practices and activities to achieve certain objectives and produce a set of outputs in support of achieving overall IT-related goals." In turn, these processes can be split into those concerning governance and those pertaining to enterprise management. Governance processes include practices and activities aimed at evaluating strategic options, providing direction to IT, and monitoring the outcome. In contrast, management processes cover responsibility for planning, building, running, and monitoring. Between them, they provide end-to-end coverage of IT throughout the health system (Figure 13). It is important to separate governance from the management function.

Figure 13: Differentiating Governance and Management

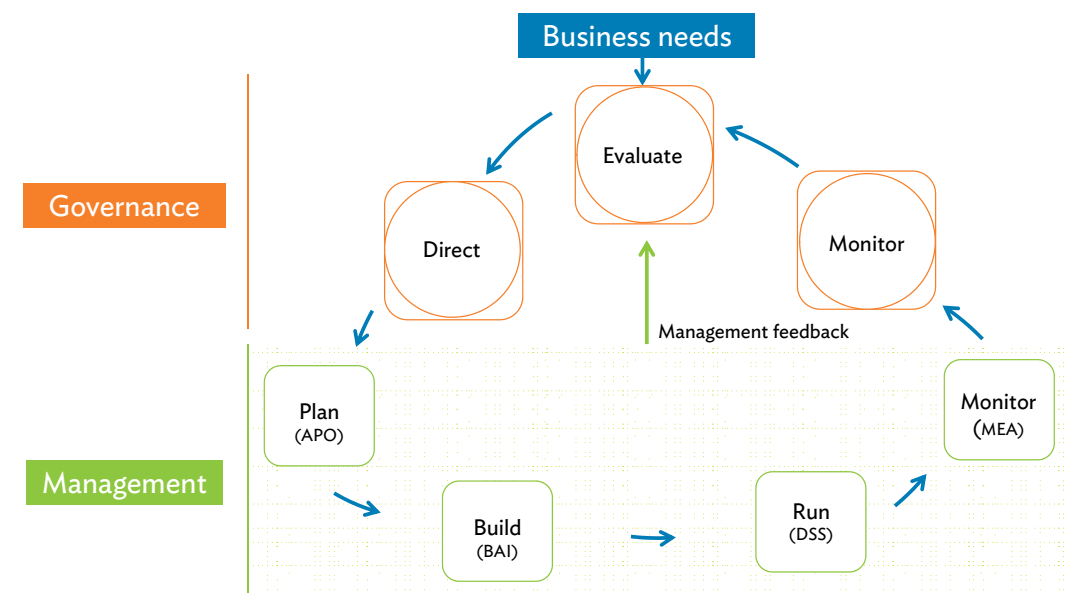

$\mathrm{APO}=$ align, plan, and organize; $\mathrm{BAI}$ = build, acquire, and implement; DSS = deliver, service, and support; $M E A=$ monitor, evaluate, and asses.

Source: Adapted from COBIT 5. 


\section{STEPS TO STRONG DIGITAL HEALTH GOVERNANCE}

Provision of health care is a complex process in almost every society, with many stakeholders involved. As such, there is no straight path to a perfect digital health system, but it is possible to manage risk using a stepwise approach. The WHO's call to action on digital health governance includes promotion of country and global governance with citizen and community participation for accountability. This can be achieved through monitoring and regular, inclusive transparent reviews of progress and performance at the facility, subnational, national, regional, and global levels. This monitoring should be linked to the targets of the health-related Sustainable Development Goals..$^{10}$

A digital health governance framework must be able to respond to changing needs and objectives as digital health evolves throughout the development of the health sector.

Steps towards strong governance:

- Define the digital health enterprise and identify all stakeholders across agencies.

- Agree on what needs to be governed, define aspects of digital health that need governance such as architecture, assets, standards, and applications.

- Agree on instruments to be used for governance, such as a digital health strategy, update the legal framework and assess investments needed.

- Define who has leadership, and convene all agencies and entities holding key resources such as ministries responsible for ICT and for statistics, health insurance providers, and private sector supporters into a national digital steering committee or similar body.

- Adopt a digital health governance framework, define levels of governance needed to be executed at central and subnational levels, depending on the decentralization and public-private health care provider mix of the country.

- Identify performance measures and monitoring processes for the adopted framework to ensure accountability and promote improvement of the health system towards patient-centric and integrated care.

- Revisit, update, and keep the governance framework active according to changing requirements of the digital health enterprise with advancing technological adoption.

Finally, amid all of this complexity, it is important to remember the bigger purposes: to ensure equitable and affordable access to quality health services for each subject of care, and to improve and protect population health.

10 World Bank, United States Agency for International Development, and WHO. Health Measurement and Accountability Post 2015: Five-Point Call to Action. http://www.searo.who.int/entity/health_situation_trends/5-point-call-to-action. pdf?ua=1. 


\section{APPENDIX}

\section{Health ICT Governance Architecture Framework (HIGAF) 2.0 - Repository}

\begin{tabular}{|c|c|c|c|c|c|c|c|}
\hline \multirow[b]{2}{*}{$\begin{array}{l}\text { Governance } \\
\text { Principles }\end{array}$} & \multicolumn{7}{|c|}{ HIGAF Components } \\
\hline & $\begin{array}{l}\text { Leadership and } \\
\text { Governance }\end{array}$ & $\begin{array}{c}\text { Strategy } \\
\text { and Investment }\end{array}$ & $\begin{array}{l}\text { Services and } \\
\text { Applications }\end{array}$ & $\begin{array}{l}\text { Standards and } \\
\text { Interoperability }\end{array}$ & Infrastructure & $\begin{array}{l}\text { Legislation, } \\
\text { Policy, and } \\
\text { Compliance }\end{array}$ & Workforce \\
\hline Policies & $\begin{array}{l}\text { Steering } \\
\text { committee } \\
\text { establishment }\end{array}$ & $\begin{array}{l}\text { Health sector } \\
\text { Plan } \\
\text { eHealth/HIS } \\
\text { master plan } \\
\text { Health budget } \\
\text { ICT budget }\end{array}$ & $\begin{array}{l}\text { Minimum } \\
\text { electronic } \\
\text { services for } \\
\text { health facilities }\end{array}$ & $\begin{array}{l}\text { Health Data } \\
\text { Standards Policy } \\
\text { Electronic Claims } \\
\text { Policy }\end{array}$ & $\begin{array}{l}\text { Cloud First } \\
\text { Policy } \\
\text { Free Wi-Fi in } \\
\text { public } \\
\text { facilities }\end{array}$ & $\begin{array}{l}\text { UHC policy } \\
\text { Health } \\
\text { insurance } \\
\text { policy } \\
\text { Privacy } \\
\text { policy } \\
\text { Security } \\
\text { policy }\end{array}$ & $\begin{array}{l}\text { COBIT } \\
\text { training }\end{array}$ \\
\hline Guidelines & $\mathrm{COBIT}_{5} \mathrm{EDM}$ & COBIT 5 APO6 & $\begin{array}{l}\text { COBIT BAI/ } \\
\text { DSS }\end{array}$ & $\begin{array}{l}\text { OpenHIE, HL7, } \\
\text { IHE }\end{array}$ & ITIL & SDGs & $\mathrm{COBIT}_{5}$ \\
\hline Best practices & $\begin{array}{l}\text { Broadband } \\
\text { commission } \\
\text { report }\end{array}$ & $\begin{array}{l}\text { WHO/ITU } \\
\text { toolkit } \\
\text { ADB AeHIN } \\
\text { costing tool }\end{array}$ & $\begin{array}{l}\text { basic EMR } \\
\text { Features }\end{array}$ & & ITIL/ITSM & ISO 27001 & AHIMA \\
\hline Standards & ISO 38500 & $\mathrm{ISO}_{38500}$ & $\begin{array}{l}\text { ISO } 27001 / 1 S O \\
20000\end{array}$ & $\begin{array}{l}\text { HL7, IHE, ISO TC } \\
215\end{array}$ & $\begin{array}{l}\text { ITIL/ISO } \\
20000\end{array}$ & & $\begin{array}{l}\text { ISO TR } \\
14639\end{array}$ \\
\hline Use case & $\begin{array}{l}\text { Philippines } \\
\text { Malaysia }\end{array}$ & Singapore & Kenya EMR & Taipei,China & Philippines & $\begin{array}{l}\text { Hong Kong, } \\
\text { China }\end{array}$ & Canada \\
\hline
\end{tabular}




\section{Transforming Health Systems Through Good Digital Health Governance}

Information and communication technology (ICT) in health systems-or digital health-can accelerate health system reforms for better quality, efficient, and accessible patient-centered care. Digital health has been acknowledged as a building block for universal health coverage. However, many countries still lack a holistic approach to digital health. This paper highlights efforts to develop a health ICT governance architecture framework through consultations and close collaboration with experts. The framework is expected to meet the evolving needs of developing member countries on digital health. Technology will continue to impact the region as broadband and mobile coverage become increasingly prevalent. By 2015, 2.5 billion people were mobile phone subscribers, with 600 million new subscribers expected by 2020 .

\section{About the Asian Development Bank}

ADB's vision is an Asia and Pacific region free of poverty. Its mission is to help its developing member countries reduce poverty and improve the quality of life of their people. Despite the region's many successes, it remains home to a large share of the world's poor. ADB is committed to reducing poverty through inclusive economic growth, environmentally sustainable growth, and regional integration.

Based in Manila, ADB is owned by 67 members, including 48 from the region. Its main instruments for helping its developing member countries are policy dialogue, loans, equity investments, guarantees, grants, and technical assistance.

$\mathrm{ADB}$ 